\title{
Prevalence and phenotypic characterization of Salmonella enterica isolates from three species of wild marine turtles in Grenada, West Indies
}

Jonnel J. Edwards ${ }^{1}$ (D), Victor A. Amadi1 (iD, Esteban Soto² (iD), Michele T. Jay-Russel ${ }^{3}$ (D), Peiman Aminabadi ${ }^{3}$ (D), Kirsten Kenelty ${ }^{4}$, Kate Charles $^{5}$, Gitanjali Arya ${ }^{6}$, Ketna Mistry ${ }^{6}$, Roxanne Nicholas ${ }^{1}$, Brian P. Butler ${ }^{1}$ (D) and David Marancik ${ }^{1}$ (D)

1. Department of Pathobiology, School of Veterinary Medicine, St. George's University, Grenada, West Indies; 2. Department of Pathobiology, School of Veterinary Medicine, University of California-Davis, Davis, California, USA; 3. Western Center for Food Safety, University of California, Davis, California, USA; 4. Department of Medicine and Epidemiology, School of Veterinary Medicine, University of California, Davis, California, USA; 5. Ocean Spirits Inc., Grenada, West Indies; 6. Office of International des Epizooties Salmonella Reference Laboratory, National Microbiology Laboratory, Public Health Agency of Canada, Guelph, Ontario, Canada.

Corresponding author: Jonnel J. Edwards, e-mail: jedward6@sgu.edu

Co-authors: VAA: vamadi@sgu.edu, ES: sotomartinez@ucdavis.edu, MTJ: mjay@ucdavis.edu, PA: amin@ucdavis.edu, KK: kvmalm@ucdavis.edu, KC: kate@oceanspirits.org, GA: gitanjali.arya@canada.ca, KM: ketna.mistry@canada.ca, RN: rnichola@sgu.edu, BPB: bbutler@sgu.edu, DM: dmaranci@sgu.edu

Received: 10-07-2020, Accepted: 10-12-2020, Published online: 25-01-2021

doi: www.doi.org/10.14202/vetworld.2021.222-229 How to cite this article: Edwards JJ, Amadi VA, Soto E, Jay-Russel MT, Aminabadi P, Kenelty K, Charles K, Arya G, Mistry K, Nicholas R, Butler BP, Marancik D (2021) Prevalence and phenotypic characterization of Salmonella enterica isolates from three species of wild marine turtles in Grenada, West Indies, Veterinary World, 14(1): 222-229.

\begin{abstract}
Background and Aim: Salmonella enterica causes enteric disease in mammals and may potentially be transmitted from marine turtles that shed the pathogen in the environment. Marine turtle-associated human salmonellosis is a potential public health concern in Grenada, as the island supports populations of leatherback turtles (Dermochelys coriacea), hawksbill turtles (Eretmochelys imbricata), and green turtles (Chelonia mydas) that interface with veterinarians and conservation workers, the local population, and the thousands of visitors that frequent the island yearly. To date, the prevalence of $S$. enterica has only been examined in a small subset of marine turtles in the Caribbean and no studies have been conducted in Grenada. The aim of this study was to quantify the prevalence of $S$. enterica in leatherback, hawksbill and green turtles in Grenada, characterize phenotypes and DNA profiles, and explore the potential risk to human health in the region.
\end{abstract}

Materials and Methods: A total of 102 cloacal swabs were obtained from nesting leatherback turtles and foraging hawksbill and green turtles. Samples were cultured on enrichment and selective media and isolates were phenotypically characterized using serotyping, pulsed-phase gel electrophoresis, and antibiotic susceptibility. Enrichment broths were additionally screened by polymerase chain reaction (PCR) using $S$. enterica-specific primers.

Results: S. enterica was cultured from 15/57 (26.3\%) leatherback turtles, 0/28 hawksbill, and 0/17 green turtles. This included S. enterica serovars Montevideo, S. I:4,5,12:i:-, Salmonella Typhimurium, Salmonella Newport, S. I:6,7:-:-, and $S$. I:4,5,12:-:-. Five/15 leatherback turtles carried multiple serovars. Eight pulsotype groups were identified with multiple clustering; however, there was no clear association between pulsotype group and serotype profile. Five/71 isolates showed resistance to streptomycin or ampicillin. Twenty-one/57 leatherback turtles, 14/28 hawksbill turtles, and 8/17 green turtles tested positive for S. enterica by quantitative PCR.

Conclusion: Nesting leatherback turtles actively shed $S$. enterica and poses a risk for zoonosis; however, the presence of viable pathogen in green and hawksbill species is unclear. These findings help elucidate the role of marine turtles as potential sources of zoonotic $S$. enterica and provide baseline data for one health research in Grenada and the wider Caribbean region.

Keywords: antimicrobials, marine turtles, pulsotypes, Salmonella enterica, serotypes, zoonosis.

\section{Introduction}

Salmonella enterica is a Gram-negative, facultative anaerobic bacterium that causes an estimated 3.8 million reported illnesses and 155,000 deaths per year worldwide [1]. There are over 2,500 serotypes, some of which are zoonotic and have shown

Copyright: Edwards, et al. Open Access. This article is distributed under the terms of the Creative Commons Attribution 4.0 International License (http://creativecommons.org/licenses/ by/4.0/), which permits unrestricted use, distribution, and reproduction in any medium, provided you give appropriate credit to the original author(s) and the source, provide a link to the Creative Commons license, and indicate if changes were made. The Creative Commons Public Domain Dedication waiver (http:// creativecommons.org/publicdomain/zero/1.0/) applies to the data made available in this article, unless otherwise stated. varying levels of pathogenicity [2]. S. enterica lives as normal flora in the intestinal tract of some vertebrates and is subsequently shed into the environment by fecal contamination where it can survive for long periods of time outside the host [3]. Human exposure occurs through direct contact with carrier animals [4], or by ingestion of contaminated food such as eggs, vegetables [5,6], and raw or undercooked meats [7].

$S$. enterica is the most commonly isolated human enteropathogen in Grenada [8] and the greater Caribbean region [9]. Despite an estimated 69\% of enteric illnesses being unreported, Grenada incurs an annual cost of $\$ 703,950$ USD associated with treatment of acute gastroenteritis [8]. This data suggest 
that the health impacts and financial cost from this disease are substantial. Grenada would benefit from having a better understanding of the exposure risks of Salmonella-associated infectious gastroenteritis on the island as well as the potential for antibiotic resistance [10]. The risk of zoonosis is greater in developing countries due to the close proximity between agriculture and communities [11]. In Grenada, farming and fishing practices are established within communities which may increase human exposure to animal reservoirs and potentially contaminated soil or sand. S. enterica has been isolated from various terrestrial animals on the island such as cane toads (Bufo marinus) [12], Indian mongooses (Herpestes auropunctatus) [13], blue land crabs (Cardisoma guanhumi) [14], and iguanas (Iguana iguana) [15]. Among these studies, the most commonly isolated serotypes were S. enterica serovar Montevideo, Salmonella Rubislaw, Salmonella Newport, Salmonella Javiana, and Salmonella Oranienburg - all serotypes previously described as potentially zoonotic [16-19]. Sporadic resistance to tetracycline, streptomycin, amoxicillin, and ampicillin were observed $[12,13]$. Marine turtles may also represent a potential source of zoonosis for S. enterica in Grenada. Consumption of green turtle (Chelonia mydas) meat has been linked with disease outbreaks of Salmonella Muenchen [20] and Salmonella Chester [21] in Australia. An uncharacterized $S$. enterica isolate has been cultured from leatherback turtle eggs in Grenada [22], which is historically consumed by the local population. In the Caribbean island of St. Kitts, S. enterica was cultured from the cloaca of $3 / 21$ [23] and 2/9 [24] leatherback turtles while 14 hawksbill turtles (Eretmochelys imbricata) and nine green turtles were culture-negative [24]. Among the obtained isolates in leatherback turtles, serotypes Montevideo and Newport were most prevalent indicating potential zoonotic risks. Grenada supports similar, although larger, population of marine turtles including nesting leatherback turtles as well as foraging and nesting populations of hawksbill and green turtles. These species interface with local and tourist populations and may pose a risk of zoonosis in three ways: (1) Consumption of contaminated turtle meat and eggs during the legal hunting season [25], (2) handling of turtles and eggs by conservation and veterinary personnel on the island, and (3) fecal contamination of sand during the 5 months nesting season and inshore waters year-round, posing a potential risk to those who utilize these areas for fishing, ecotourism, or recreation.

The goal of this study was to quantify the prevalence of S. enterica in leatherback, hawksbill and green turtles in Grenada, characterize phenotypes and DNA profiles, and explore the potential risk to human health in the region. As there are limited reports on the prevalence and characteristics of $S$. enterica in marine turtles in the Caribbean region, data from this study will further establish the role of a statistically significant population of marine turtles in the dissemination of the pathogen in the marine environment.

\section{Materials and Methods}

\section{Ethical approval}

The protocol and procedures of this study were approved by the St. George's University Institutional Animal Care and Use Committee (IACUC-16017-R) and approval and permitting was obtained from the Grenada Ministry of Agriculture, Forestry, Lands, and Fisheries.

\section{Sampling, study period, and location}

Cloacal cultures were obtained from nesting leatherback turtles from April to August 2017 on Levera Beach, Grenada (Figure-1). Samples were obtained under long-wavelength light and immediately following oviposition, defined by the expulsion of yolkless eggs, to avoid disrupting the nesting process. Foraging hawksbill and green turtles were sampled in this same region offshore during the day (Figure-1). Turtles were hand-caught by free-divers and taken aboard a boat within $30 \mathrm{~s}$ of capture. To obtain cloacal samples, the tail was gently lifted to identify the cloaca and a sterile culturette (Thermo Scientific Remel BactiSwab, USA) was inserted approximately $5 \mathrm{~cm}$ into the cloaca and spun 6 times [23]. Culturettes were placed on ice for field storage until transfer to St. George's University,

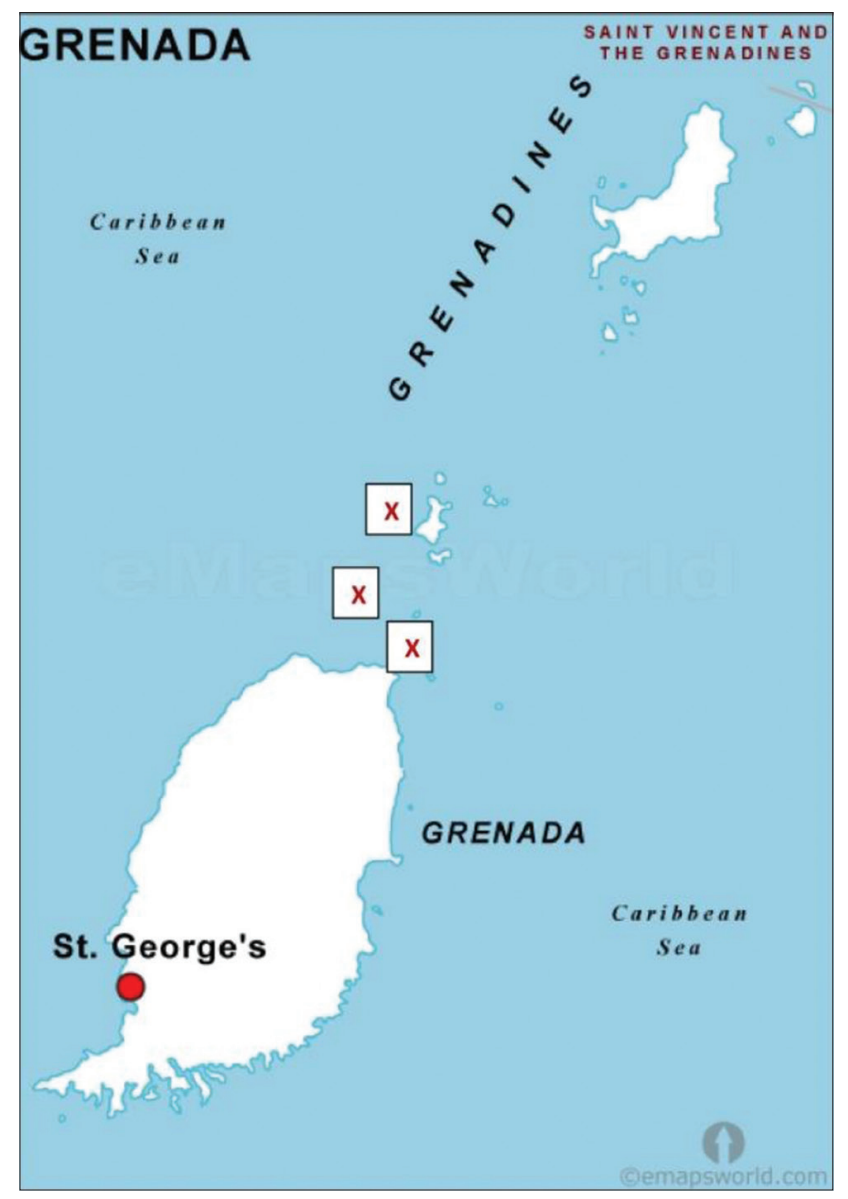

Figure-1: Map of Grenada showing sample collection sites (X). [Source: https://emapsworld.com/grenada-capitalmap.html, pasted onto image by Jonnel Edward]. 
School of Veterinary Medicine for bacterial culture within $24 \mathrm{~h}$ of sample collection.

\section{Isolation and identification of $\boldsymbol{S}$. enterica}

Each cloacal swab was transferred to $10 \mathrm{~mL}$ trypticase soy enrichment broth (TSB) (BD Bacto, Sparks, MD, USA) and incubated at $37^{\circ} \mathrm{C}$ for $24 \mathrm{~h}$ in static conditions. Following incubation, $100 \mu \mathrm{L}$ of each sample in TSB was aliquoted into $10 \mathrm{~mL}$ Rappaport-Vassiliadis enrichment broth (Oxoid, Hants, UK) and incubated at $47^{\circ} \mathrm{C}$ for $48 \mathrm{~h}$ in static conditions. The remainder of samples in TSB was stored at $-80^{\circ}$ for quantitative polymerase chain reaction (qPCR). Following incubation, $100 \mu \mathrm{L}$ of each sample was streaked onto one plate of xylose lysine deoxycholate (XLD, CA, USA) agar (Criterion dehydrated culture media) which is selective for Salmonella spp. [26] and incubated at $37^{\circ} \mathrm{C}$ for $24 \mathrm{~h}$ in aerobic conditions. To explore the presence of mixed-serovar infections within one sample, 1-5 individual colonies per plate with typical Salmonella spp. morphology (colonies with a black center) were re-streaked onto XLD agar, and incubated at $37^{\circ} \mathrm{C}$ for $24 \mathrm{~h} \mathrm{[27].} \mathrm{Single} \mathrm{colonies} \mathrm{from} \mathrm{the} \mathrm{XLD}$ agar were sub-cultured on trypticase soy agar plates (BD Difco, Sparks, MD, USA) at $37^{\circ} \mathrm{C}$ for $24 \mathrm{~h}$. Resulting individual colonies were tested for agglutination using Salmonella $\mathrm{O}$ antiserum poly A-I and Vi (BD Difco ${ }^{\mathrm{TM}}$ ). Agglutination-positive cultures were inoculated onto analytical profile index strips (API$20 \mathrm{E}^{\circledR}$ ) for preliminary identification of Salmonella spp. Reference strain S. enterica subspecies enterica ATCC13311 was used as a positive control [28]. Identified pure Salmonella cultures were stored in $10 \%$ sterile skim milk solution at $-80^{\circ} \mathrm{C}$.

DNA was isolated from $1.5 \mathrm{~mL}$ TSB broth using the DNEasy Blood and Tissue Kit (QUIAGEN, Hilden, Germany) following manufacturer's protocol. As a minor modification to eliminate any inhibitors contained in TSB, $1.5 \mathrm{~mL}$ of broth was centrifuged for $5 \mathrm{~min}$ and pellets were washed with 0.2 $\mathrm{mL}$ phosphate-buffered saline before carrying out the kit protocol. DNA products were nanodropped and normalized to $\sim 50 \mathrm{ng} / \mu \mathrm{L}$ DNA concentration, and run in triplicate $\mathrm{qPCR}$ reaction using the invA probe (FAM-CGTCACCTTTGATAAACTTCATCGCABHQ1) and primer sets (forward AGCGTACTGGAAAGGGAAAG; reverse 3'-5' ATACCGCCAATAAAGTTCACAAAG) [29].

Serotyping [30,31] was performed on all cultured isolates by the World Organization for Animal Health (Office International des Epizooties; OIE) Salmonella Reference Laboratory of the Public Health Agency of Canada's National Microbiology Laboratory at Guelph, Ontario, Canada [32]. Serovars were named based on an established antigenic formula [33].

Pulsotyping was performed on whole bacterial cultures of 15 randomly selected isolates using pulsefield gel electrophoresis (PFGE) to examine the DNA fingerprint and genetic clonality of Salmonella isolates obtained from leatherback cloacal swabs [34].

\section{Antimicrobial sensitivity of $\boldsymbol{S}$. enterica isolates}

Antimicrobial sensitivity was determined using the standard Kirby-Bauer disk diffusion method on Mueller-Hinton agar (Remel, KS, USA), and zones of inhibition were measured as recommended by the Clinical and Laboratory Standards Institute [35] using S. enterica subspecies enterica ATCC13311 as a reference strain. Salmonella isolates were tested against the following drugs: Cefotaxime $(30 \mu \mathrm{g})$, ceftazidime $(30 \mu \mathrm{g})$, nalidixic acid $(30 \mu \mathrm{g})$, ciprofloxacin $(5 \mu \mathrm{g})$, streptomycin $(10 \mu \mathrm{g})$, amoxicillin-clavulanic acid (30 $\mu \mathrm{g})$, ampicillin $(30 \mu \mathrm{g})$, enrofloxacin $(5 \mu \mathrm{g})$, gentamicin $(10 \mu \mathrm{g})$, sulfamethoxazole $(23.75 \mu \mathrm{g})$, and tetracycline $(30 \mu \mathrm{g})$ (BD Difco, Sparks, MD, USA). These antimicrobials were selected based on their common use for treatment of Salmonellosis in Grenada [27].

\section{Statistical analysis}

Prevalence level of $S$. enterica by culture and qPCR was compared using an unpaired t-test and prevalence levels were compared between leatherback, hawksbill, and green turtles using a one-way analysis of variance. All statistics were run with a significance level of $\mathrm{p}<0.05$.

\section{Results}

S. enterica was cultured from cloacal swabs from $15 / 57(26.3 \%)$ nesting leatherback turtles, $0 / 28$ foraging hawksbill turtles, and 0/17 foraging green turtles (Table1). When examined by quantitative PCR, prevalence increased to $21 / 57$ (36.8\%) in leatherback turtles, $14 / 28$ $(50 \%)$ in hawksbill turtles, and 8/17 (47\%) in green turtles (Table-1). Salmonella Montevideo was the most commonly cultured serotype, followed by $S$. I:4,5,12:i:-, Salmonella Typhimurium, $S$. Newport, $S$. I:6,7:-:-, and S. I:4,5,12:-:-, respectively. Five/15 (33.3\%) turtles carried multiple serovars (Table-2). Fifteen $S$. enterica isolates examined by PFGE comprised eight distinct pulsotypes with multiple clustering between groups and no clear association between pulsotype groups and serotype profiles (Figure-2). Five/71 (7.1\%) isolates showed resistance to streptomycin or ampicillin.

\section{Discussion}

The goal of this study was to isolate and phenotypically characterize $S$. enterica from cloacal samples of leatherback, hawksbill, and green turtles found in Grenada and to compare prevalence among each turtle species. Overall, the prevalence of $S$. enterica was higher in leatherback turtles compared with hawksbill and green turtles by bacterial culture; however, there was no statistically significant difference in prevalence among the three species when examined by qPCR. Serovars $S$. I:4,5,12:i:-, $S$. I:4,5,12:-:- and $S$. I:6,7:-:- were isolated for the first time from leatherback turtles and eight distinct pulsotype groups were characterized and comprised isolates with varying 
Table-1: Prevalence of Salmonella enterica in the cloaca of leatherback, hawksbill, and green turtles using bacterial culture and qPCR.

\begin{tabular}{lccc}
\hline Turtle species & $\mathbf{n}$ & $\begin{array}{c}\text { Number of positive turtles by bacterial } \\
\text { culture (\%) }\end{array}$ & $\begin{array}{c}\text { Number of positive turtles } \\
\text { by qPCR (\%) }\end{array}$ \\
\hline Leatherback & 57 & $15(26.3)$ & $21(36.8)$ \\
Hawksbill & 28 & 0 & $14(50.0)$ \\
Green & 17 & 0 & $8(47.0)$ \\
\hline
\end{tabular}

$\mathrm{qPCR}=$ Quantitative polymerase chain reaction

Table-2: Mixed Salmonella enterica serovars isolated from single cloacal cultures from leatherback turtles.

\begin{tabular}{lcc}
\hline $\begin{array}{l}\text { Leatherback } \\
\text { sample no. }\end{array}$ & $\begin{array}{c}\text { Number of serotypes } \\
\text { isolated }\end{array}$ & Serotypes identified \\
\hline L14 & 2 & S. Montevideo, S. I:6,7:-:- \\
L36 & 3 & S. Montevideo, S. Typhimurium, S. I:4,5,12:i:- \\
L37 & 2 & S. Montevideo, S. I:4,5,12:i:- \\
L40 & 2 & S. Typhimurium, S. I:4,5,12:i:- \\
L45 & 4 & S. Montevideo, S. Typhimurium, S. I:4,5,12:i:-, S. I:4,5,12:-:- \\
\hline
\end{tabular}

S=Salmonella, S. Montevideo=Salmonella Montevideo, S. Typhimurium=Salmonella Typhimurium

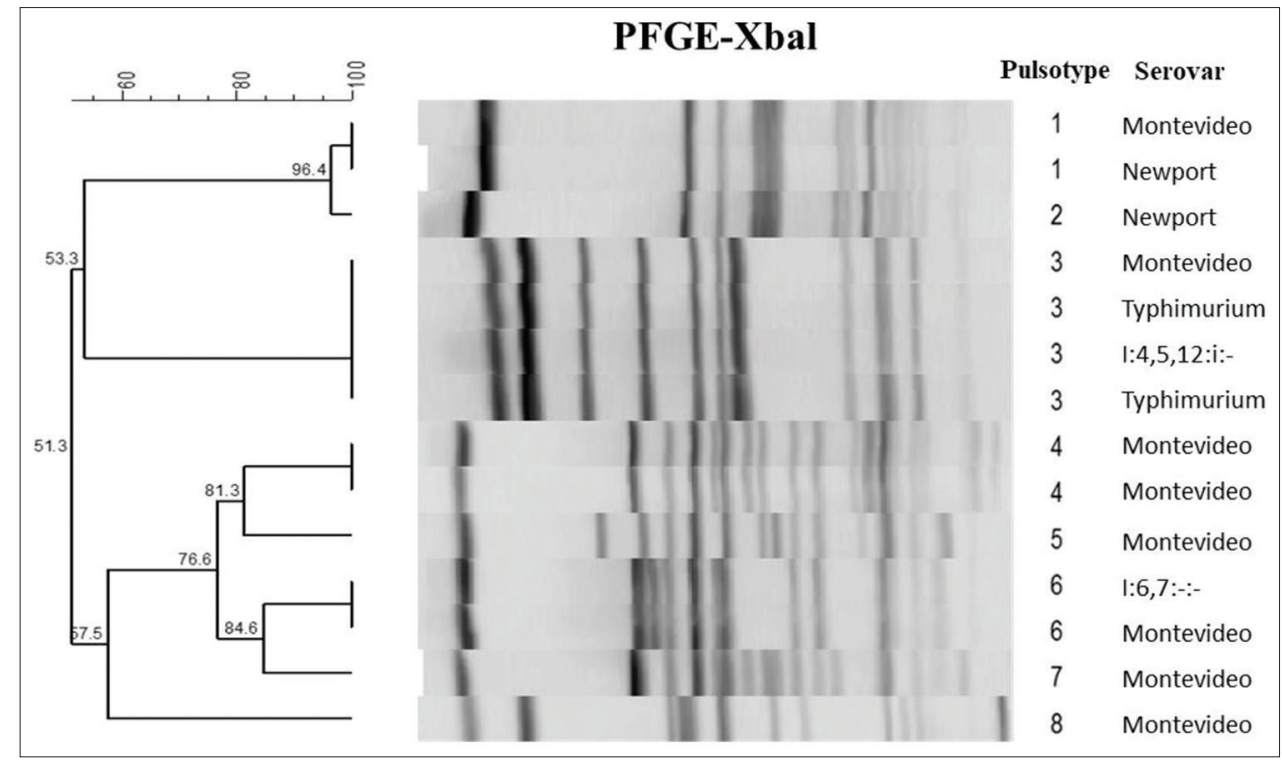

Figure-2: Pulsotype group and associated serotype of 15 randomly selected Salmonella enterica isolates.

serotypes. Results from this study help elucidate the role of marine turtles as carriers of $S$. enterica and the zoonotic risk they pose when they interface with humans.

The $24 \%$ prevalence of $S$. enterica in nesting leatherback turtles by culture was similar to the $14 \%$ [23] recovery found in nesting leatherback turtles in St. Kitts. In addition, similar to results described in this study, foraging hawksbill and green turtles were also culture-negative in St. Kitts. When examined by qPCR, however, $S$. enterica was detected in $7 \%$ and $0 \%$ of hawksbill and green turtles in St. Kitts, respectively [24], which is considerably lower than the 50\% and $47 \%$ prevalence demonstrated, respectively, in hawksbill and green turtles in Grenada. This disparity in prevalence by molecular methods may be attributed to the larger sample size, difference in specificity of primer sets, or it may represent an epidemiologic difference between regions of the Caribbean.
Recovery of viable $S$. enterica from leatherback turtles but not hawksbill or green turtles suggests that leatherback turtles were more actively shedding the bacteria at the time of sampling. The circumstances associated with this finding are unknown but may be multifactorial. As logistical and size constraints limit accessibility to foraging leatherback turtles, samples were obtained while leatherback turtles nested on the beach. Samples from hawksbill and green turtles were obtained while they foraged in open coastal waters as they do not typically nest on the mainland of Grenada. This limitation naturally biased the sample population to include sexually mature, female leatherback turtles and a mix of male/female and sexually mature/immature hawksbill and green turtles. In addition to age and gender differences, the act of nesting may also affect culture results. It is possible that egg laying increases viable $S$. enterica within the cloacal cavity during oviposition as transmission of Salmonella spp. to the egg has been described 
in leatherback turtles [22]. Immunosuppression has been shown to increase proliferation and shedding of bacteria, including $S$. enterica, in mammals and other cold-blooded species [36-38]. Although the effect of nesting on the immune response in sea turtles is relatively uncharacterized, leatherback turtles may potentially be stressed during nesting and therefore shed the pathogen more actively than non-nesting hawksbill and green turtles. Nesting leatherback turtles had contact with the sand while foraging hard-shell turtles did not, especially male and juvenile turtles as only mature females return to land once hatched. The effect that sand contact may have on dissemination of $S$. enterica in turtles is unknown. S. enterica has been detected by PCR in sand within leatherback turtle nests [24]. It is possible that bacterial contamination of the sand could result in transmission of $S$. enterica to nesting turtles that subsequently come ashore to nest. This may be further explored by examining the presence of $S$. enterica from sand in nests in Grenada and by sampling nesting hardshell turtles, or if logistically feasible, sampling foraging leatherback turtles.

Salmonella Montevideo was the most commonly isolated serovar as it was found in two-third of isolates from culture-positive leatherback turtles. This is similar to findings in St. Kitts [23] and this relatively high prevalence distinguishes $S$. Montevideo as a public health risk for salmonellosis from marine turtles. This serovar is known to cause enteric disease outbreaks in humans $[39,40]$ and has been described as environmentally robust due to its ability to form biofilms $[41,42]$ and acts as a long-term environmental contaminant [43]. The presence of $S$. Montevideo in both marine and terrestrial cold-blooded and warm-blooded vertebrates as well as invertebrates [12-14] highlights its potential zoonotic risk at the wildlife-human interface in Grenada. Subsequent research into the genetic relatedness of isolates from these different species may provide further understanding of host-bacterial interactions and epidemiology of $S$. enterica on the island.

$S$. Typhimurium, $S$. I:4,5,12:i:-, and $S$. Newport were also relatively common at $20-30 \%$ prevalence in culture-positive turtles and all have been associated with salmonellosis [44]. $S$. Typhimurium has been described as a multidrug-resistant, invasive serovar with varying degrees of host adaptation [45] and can cause aggressive gastroenteritis in humans [46]. Multidrug resistance was not observed in $S$. Typhimurium isolates in this study. Salmonella I:4,5,12:i:- is a monophasic variant of $S$. Typhimurium (antigenic formula 4, [5], 12:i:1,2). It has been described to be genetically closely related to $S$. Typhimurium $[47,48]$ with a similar pathogenicity gene repertoire, although phenotypic differences in motile capacity and cell adhesion have been described [49]. Salmonella I:4,5,12:i:- has been described as a potential health risk to humans based on transmission from farmed pigs during processing [48]. $S$. Newport, previously described as zoonotic, appears to be relatively prevalent in leatherback turtles [24] and green iguanas [15]. Salmonella I:6,7:-:- and S. I:4,5,12:-:-, which were each isolated from one leatherback turtle, have not been well characterized and there are no reports of human infection in the literature to indicate their pathogenicity or potential zoonotic risk.

There were five instances where multiple Salmonella serovars were isolated from the same cloacal sample. This included two turtles that carried $S$. Montevideo, $S$. Typhimurium, and $S$. I:4,5,12:i:and one turtle each that carried $S$. Montevideo and $S$. I:4,5,12:i:-, $S$. Typhimurium and $S$. I:4,5,12:i:-, and $S$. Montevideo and $S$. I:6,7:-:-. To the best of our knowledge, this is the first description of multi-serovar infections in marine turtles. Multi-serovar carriers have been described in other species including iguanas and mongooses in Grenada $[13,15]$ and the combination of serovars that were isolated from these terrestrial species was not similar to those found in leatherback turtles. The carriage of multiple Salmonella serovars indicates the potential for leatherback turtles to transfer mixed infections to humans which has been previously described from terrestrial food animals [50,51]. Multi-serovar infection in farmed animals and retail meats has been associated with transfer of antibiotic resistance genes between isolates [52,53]. Although exposure of marine turtles to antibiotics and development of drug-resistant bacteria is likely minimal, the risk of agricultural run-off in the dissemination of multidrug-resistant $S$. enterica isolates to marine turtles warrants investigation.

There was no clear relationship between serovar profiles and pulsotype groups for the $15 \mathrm{~S}$. enterica isolates examined. For example, eight $S$. Montevideo isolates were spread between seven different pulsotype groups and often clustered more closely with isolates from other serovars rather than with each other. This included pulsotype Group 3 that was comprised $S$. Montevideo, two $S$. Typhimurium isolates, and $S$. I:4,5,12:i:-. Similar findings have been described in $S$. enterica isolates from poultry [54], indicating that within this bacterial species there is little association between expressed surface antigens and large DNA genotypic profiles. The advantage of pulsotyping in contrast to serotyping to establish epidemiology is unknown, and the association of pulsotype groups with pathogenicity or host-type is unclear. Therefore, it may be pertinent to conduct pulsotyping of $S$. enterica isolates archived from previous studies of terrestrial species in Grenada. This may better establish genetic clonality among isolates between species and help elucidate the role of these animals in the epidemiology of salmonellosis.

Isolates were largely sensitive to the antimicrobials tested, with sporadic evidence of resistance. The most prevalent resistance was to streptomycin in 7\% of isolates. Studies of green iguanas and Indian mongooses in Grenada have shown intermediate resistance to streptomycin $[13,15]$. Similar findings have also 
been published outside the Caribbean region, where resistance to streptomycin was observed in S. enterica isolates cultured from slaughtered bovines and ovines in Ethiopia [55]. The varying levels of antimicrobial sensitivity to streptomycin may potentially impact the use of this drug to treat salmonellosis.

Thirty-seven/102 (36.2\%) turtles that were culture-negative were interpreted as positive by qPCR. This result was anticipated based on the relatively higher sensitivity of the qPCR assay. Although $S$. enterica may have been present in the cloaca, it may not have proliferated on the media used, at the specific temperature and incubation period, or it may have been outcompeted by less fastidious bacteria. In addition, not all Salmonella spp. strains are hydrogen sulfide-positive [56] and therefore some positive samples may have been missed due to selection of colonies based on this particular phenotype. These results indicate the importance of using multiple detection methods for the surveillance of various strains of $S$. enterica from animals.

This research has compiled statistically significant data on the prevalence and characteristics of $S$. enterica in marine turtles in the region. There are no available data regarding phenotypic or genotypic characteristics of human isolates of S. enterica in Grenada, and therefore we cannot determine at this time that marine turtles are a confirmed source of human salmonellosis on the island. However, due to the interface that humans in Grenada share with marine turtles, it is reasonable to suggest that these reptiles are a potential source of zoonotic transmission. Further sampling in marine turtles, sand, and water may provide additional epidemiologic data to elucidate the role of these species in spreading $S$. enterica in the environment. This information also will drive educational guidelines to reduce the risk of salmonellosis in fisherman, veterinarians, ecotourists, conservation workers, and the general public who interface with these species.

\section{Conclusion}

These results demonstrate that nesting leatherback turtles actively shed $S$. enterica and pose a risk for zoonosis; however, the presence of viable pathogen in green and hawksbill species warrants examination. Baseline data from this study will propel further investigation of the zoonotic potential and public health implications of $S$. enterica carriage in marine turtles in the region.

\section{Authors' Contributions}

JJE contributed to study design, sample collection and processing, assay development, data analysis, and manuscript preparation. VAA contributed to study design, sample processing, assay development, data analysis, and manuscript preparation. ES contributed to sample processing, assay development, and manuscript preparation. MTJ and PA contributed to PFGE assay development and sample processing. KK contributed to qPCR assay development and sample processing. KC participated in sample collection. GA and $\mathrm{KM}$ contributed to assay development and sample processing. $\mathrm{RN}$ participated in sample processing. BPB contributed to study design, sample collection, and manuscript preparation. DM contributed to study design, sample collection, data analysis, and manuscript preparation. All authors read and approved the final manuscript.

\section{Acknowledgments}

The authors wish to thank Ocean Spirits staff and volunteers for their assistance in sample collection and Patrick McLaughlin for his review of this manuscript. This project was funded through the One Health Research Initiative Grant (OHRI-03-3009) provided by the Windward Islands Research and Education Foundation (WINDREF), Grenada.

\section{Competing Interests}

The authors declare that they have no competing interests.

\section{Publisher's Note}

Veterinary World remains neutral with regard to jurisdictional claims in published map and institutional affiliation.

\section{References}

1. Majowicz, S.E., Musto, J., Scallan, E., Angulo, F.J., Kirk, M., O'Brien, S.J., Jones, T.F., Fazil, A. and Hoekstra, R.M. (2010) The global burden of non-typhoidal Salmonella gastroenteritis. Clin. Infect. Dis., 50(6): 882-889.

2. Eng, S., Pusparajah, P., Mutalib, N.A., Ser, H., Chan, K. and Lee, L. (2015) Salmonella: A review on pathogenesis, epidemiology and antibiotic resistance. Front. Life Sci., 8(3): 284-293.

3. Winfield, M. and Groisman, E. (2003) Role of non-host environments in the lifestyles of Salmonella and Escherichia coli. Appl. Environ. Microbiol., 69(7): 3687-3694.

4. Demirbilek, S.K. (2017) Salmonella: A re-emerging pathogen. In: Mascellino MT, editor. Salmonellosis in Animals. Vol. 2. IntechOpen, London. p19-31.

5. Schoeni, J.L., Glass, K., McDermott, J.L. and Wong, C.L. (1995) Growth and penetration of Salmonella Enteritidis, Salmonella Heidelberg and Salmonella Typhimurium in eggs. Food Microbiol., 24(3): 385-396.

6. Islam, M., Morgan, J., Doyle, M.P., Phatak, S.C., Miller, P. and Jiang, X. (2004) Persistence of Salmonella enterica serovar Typhimurium on lettuce and parsley and in soils on which they were grown in fields treated with contaminated manure composts or irrigation water. Foodborne Pathog. Dis., 1(1): 27-35.

7. Zhao, C., Beilei, G., De Villena, J., Sudler, R., Yeh, E., Zhao, S., White, D.G., Wagner, D. and Meng, J. (2001) Prevalence of Campylobacter spp., Escherichia coli, and Salmonella serovars in retail chicken, turkey, pork, and beef from greater Washington, DC. area. Appl. Environ. Microbiol., 67(12): 5431-5436.

8. Glasgow, L.M., Forde, M.S., Antoine, S.C., Pérez, E. and Indar, L. (2013) Estimating the burden of acute gastrointestinal illness in Grenada. J. Health Popul. Nutr., 31(4 Suppl 1): 17-29.

9. Lefrançois, T., Petit, M.S., Kalloo, M., Shaw, J., HerbertHackshaw, K., Trotman, M. and Gongora, V. (2010) CaribVET: A model for surveillance of zoonotic diseases. 
Int. J. Infect. Dis., 14(1): e185.

10. Angelo, K.M., Reynolds, J., Karp, B.E., Hoekstra, R.M., Scheel, C.M. and Friedman, C. (2016) Antimicrobial resistance among non-typhoidal Salmonella isolated from blood in the United States, 2003-2013. J. Infect Dis., 214(10): $1565-1570$.

11. Grace, D. (2015) Zoonoses of poverty: Measuring and managing the multiple burdens of zoonoses and poverty. In: Sing, A., editor. Zoonoses-Infections Affecting Humans and Animals: Focus on Public Health Aspects. Springer, Dordrecht, Netherlands. p1127-1137.

12. Drake, M., Amadi, V, Zieger, U., Johnson, R. and Hariharan, H. (2013) Prevalence of Salmonella spp. in cane toads (Bufo marinus) from Grenada, West Indies, and their antimicrobial susceptibility. Zoonoses Public Health, 60(6): 437-441

13. Miller, S., Amadi, V., Stone, D., Johnson, R., Hariharan, H. and Zieger, U. (2014) Prevalence and antimicrobial susceptibility of Salmonella spp. in small Indian mongooses (Herpestes auropunctatus) in Grenada, West Indies. Comp. Immunol. Microbiol. Infect. Dis., 37(4): 205-210.

14. Peterson, R., Hariharan, H., Matthew, V., Chappell, S., Davies, R., Parker, R. and Sharma, A. (2013) Prevalence, serovars, and antimicrobial susceptibility of Salmonella isolated from blue land crabs (Cardisoma guanhumi) in Grenada, West Indies. J. Food Prot., 76(7): 1270-1273.

15. Sylvester, W.R., Amadi, V., Pinckney, R., Macpherson, C.N., McKibben, J.S., Bruhl-Day, R., Johnson, R. and Hariharan, H. (2013) Prevalence, serovars and antimicrobial susceptibility of Salmonella spp. from wild and domestic green iguanas (Iguana iguana) in Grenada, West Indies. Zoonoses Public Health, 61(6): 436-441.

16. Zettell, L., Jelsema, R. and Isada, N. (1995) First-trimester septic abortion due to Salmonella Enteritidis Oranienburg. Infect. Dis. Obstet. Gynecol., 2(5): 239-241.

17. Niizuma, T., Terada, K., Matsuda, K., Ogita, S. and Kataoka, N. (2002) Intrafamilial transmission of Salmonella Oranienburg. Pediatr. Int., 44(4): 391-393.

18. Moffatt, C.R., Lafferty, A., Khan, S., Krsteski, R., Valcanis, M., Powling, J. and Veitch, M. (2010) Salmonella Rubislaw gastroenteritis linked to a pet lizard. Med. J. Aust., 103(1): 54-55.

19. Centers for Disease Control and Prevention. (2011) National Enteric Disease Surveillance Salmonella Annual Report, 2011. Available from https://www.cdc.gov/ncezid/dfwed/ PDFs/salmonella-annual-report-2011-508c.pdf. Retrieved on 26-10-2017.

20. Draper, A.K., James, C.L., Pascall, J.E., Shield, K.J., Langrell, J. and Hogg, A. (2017) An outbreak of Salmonella Muenchen after consuming sea turtle, Northern Territory, Australia, 2017. Commun. Dis. Intell. Q. Rep., 41(4): E290-E294.

21. O'Grady, K.A. and Krause, V. (1999) An outbreak of salmonellosis linked to a marine turtle. Southeast Asian J. Trop. Med. Public Health, 30(2): 324-327.

22. Zieger, U., Trelease, H., Winkler, N., Mathew, V. and Sharma, R.N. (2009) Bacterial contamination of leatherback turtle (Dermochelys coriacea) eggs and sand in nesting chambers at Levera Beach, Grenada, West Indies preliminary study. West Indian Vet. J., 9(2): 21-26

23. Dutton, C.S., Revan, F., Wang, C., Xu, C., Norton, T.M., Stewart, K.M., Kaltenboeck, B. and Soto, E. (2013) Salmonella enterica prevalence in leatherback sea turtles (Dermochelys coriacea) in St. Kitts, West Indies. J. Zoo Wildl. Med., 44(3): 765-768.

24. Ives, A.K., Antaki, E., Stewart, K., Francis, S., JayRussel, M.T., Sithole, F., Kearney, M.T., Griffin, M.J. and Soto, E. (2016) Detection of Salmonella enterica serovar Montevideo and Newport in free-ranging sea turtles and beach sand in the Caribbean and persistence in sand and seawater microcosms. Zoonoses Public Health, 64(6): 450-459.
25. Grazette, S., Horrocks, J.A., Phillip, P.E. and Isaac, C.J. (2007) An assessment of the marine turtle fishery in Grenada, West Indies. Oryx, 41(3): 1-7.

26. Nye, K.J., Fallon, D., Frodsham, D., Gee, B., Graham, C., Howe, S., Messer, S., Turner, T. and Warren, R.E. (2002) An evaluation of the performance of XLD, DCA, MLCB, and $\mathrm{ABC}$ agars as direct plating media for the isolation of Salmonella enterica from feces. J. Clin. Pathol., 55(4): 286-288.

27. Amadi, V.A., Hariharan, H., Gitanjali, A., MatthewBelmar, V., Nicholas-Thomas, R.,, R., Sharma, R. and Johnson, R. (2017) Serovars and antimicrobial resistance of non-typhoidal Salmonella isolated from non-diarrheic dogs in Grenada, West Indies. J. Vet. Med. Sci., 4(1): 26-34.

28. Terabayashi, Y., Juan, A., Tamotsu, H., Ashimine, N, Nakano, K., Shimoji, M., Shiroma, A., Teruya, K., Satou, K. and Hirano, T. (2014) First complete genome sequence of Salmonella enterica subsp. enterica serovar Typhimurium strain ATCC 13311 (NCTC 74), a reference strain of multidrug resistance, as achieved by use of PacBio single-molecule real-time technology. Genome Announc., 2(5): e00986-14.

29. Kasturi, K.N. and Drgon, T. (2017) Real-Time PCR method for detection of Salmonella spp. in environmental samples. Appl. Environ. Microbiol., 83(14): e00644-17.

30. Shipp, C.R. and Rowe, B. (1980) A mechanized microtechnique for Salmonella serotyping. J. Clin. Pathol., 33(6): 595-597.

31. Ewing, W.H. (1986) Edwards and Ewing's Identification of Enterobacteriaceae. $4^{\text {th }}$ ed. Elsevier Science Publishing Co. Inc., New York, USA.

32. International Organization for Standardization. (2014) ISO/ TR 6579-3:2014. Microbiology of the food chain Horizontal method for the detection, enumeration and serotyping of Salmonella Part 3: Guidelines for serotyping of Salmonella spp. International Organization for Standardization, Geneva, Switzerland.

33. Grimont, P.D. (2007) Antigenic Formulas of the Salmonella Serovars. $9^{\text {th }}$ ed. WHO Collaborating Center for Reference and Research on Salmonella Institute Pareur, Paris Cedex, France.

34. Ribot, E.M., Fair, M.A., Gautom, R., Cameron, D.N., Hunter, S.B., Swaminathan, B. and Barrett, T.J. (2006) Standardization of pulsed-field gel electrophoresis protocols for the subtyping of Escherichia coli O157:H7, Salmonella, and Shigella for PulseNet. Foodborne Pathog. Dis., 3(1): 59-67.

35. Clinical Laboratory Standards Institute: CLSI Guidelines. (2018) Performance Standards for Antimicrobial Susceptibility Testing. $27^{\text {th }}$ ed. $35 . \quad$ C 1 i n i c a 1 Laboratory Standards Institute, Wayne, PA. Available from: https://www.clsi.org/standards/products/microbiology/documents/m100. Retrieved on 31-10-2018.

36. Carter, M.E. and Quinn, P.J. (2000) Salmonella infections in dogs and cats. In: Wray, C. and Wray, A., editors. Salmonella in Domestic Animals. Vol. 14. CAB International, Wallingford, Oxfordshire, UK. p231-244.

37. Parker, J.L. and Shaw, J.G. (2011) Aeromonas spp. clinical microbiology and disease. J. Infect., 62(2): 109-118.

38. Gonçalves, R.B., de Olivera, W.F., Marques, D.C., Dos Santos Correia, M.T., de Carvalho, E.M. and Coelho, L.B. (2019) The genus aeromonas: A general approach. Microb. Pathog., 130: 81-94.

39. Patel, M., Chen, S., Pringle, J., Russo, E., Aras, J., Weiss, J., Anderson, S., Sunenshine, R., Komatsu, K., Schumacher, M., Flood, D., Theobald, L., Bopp, C., Wannemuehler, K., White, P., Angulo, F.J. and Behravesh, B. (2010) A prolonged outbreak of Salmonella Montevideo infections associated with multiple locations of a restaurant chain in Phoenix, Arizona, 2008. J. Food Prot., 73(10): $1858-1863$

40. Lalsiamthara, J. and Hwa, L.J. (2017) Pathogenic Traits of 
Salmonella Montevideo in Experimental Infections in vivo and in vitro. Available from https://www.nature.com/articles/srep46232.pdf. Retrieved on 08-11-2019.

41. Steenackers, H., Hermans, K., Vanderleyden, J. and Keersmaecker, S. (2012) Salmonella biofilms: An overview on occurrence, structure, regulation and eradication. Food Res. Int., 45(2): 502-531.

42. Keelara, S., Thakur, S. and Patel, J. (2016) Biofilm formation by environmental isolates of Salmonella and their sensitivity to natural antimicrobials. Foodborne Pathog. Dis., 13(9): 509-516.

43. Gorski, L., Parker, C.T., Liang, A., Cooley, M.B., JayRussel, M.T., Gordus, A.G., Atwill, E.R. and Mandrell, R.E. (2011) Prevalence, distribution, and diversity of Salmonella enterica in a major production region of California. Appl. Environ. Microbiol., 77(8): 2734-2748.

44. Leedom, K.R. and Spickler, A.R. Salmonellosis. The Center for Food Security and Public Health Factsheet. Available from http://www.cfsph.iastate.edu/Factsheets/pdfs/nontyphoidal_salmonellosis.pdf. Retrieved on 15-04-2019.

45. Shaokang, Z., Shaoting, L., Weidong, G., Henk, B., Boxrud, D., Taylor, A., Roe, C., Driebe, E., Engelthaler, D.M., Allard, M., Brown, E., McDermott, P., Zhao, S., Bruce, B., Trees, E., Fields, P.I. and Xiangyu, D. (2019) Zoonotic source attribution of Salmonella enterica serotype Typhimurium using genomic surveillance data, United States. Emerg. Infect. Dis., 25(1): 82-91.

46. Chaudhuri, D., Chowdhury, A.R., Biswas, B. and Chakravortty, D. (2018) Salmonella Typhimurium infection leads to colonization of the mouse brain and is not completely cured with antibiotics. Front. Microbiol., 9: 1632.

47. Soyer, Y., Moreno, A.S., Davis, M.A., Maurer, J., McDonough, P.L., Schoonmaker-Bopp, D.J., Dumas, N.B., Root, T., Warnick, L.D., Gröhn, Y.T. and Wiedmann, M. (2009) Salmonella enterica serotype 4,5,12:i:-, an emerging Salmonella serotype that represents multiple distinct clones. Clin. Microbiol., 47(11): 3546-3556.

48. Hauser, E., Tietze, E., Helmuth, R., Junker, E., Blank, K., Prager, R., Rabsch, W., Appel, B., Fruth, A. and Malorny, B. (2010) Pork contaminated with Salmonella serovar
4,[5],12:1:-, an emerging health for humans. Appl. Environ. Microbiol., 76(14): 4601-4610.

49. Haiko, J. and Westerlund-Wikström, B. (2013) The role of the bacterial flagellum in adhesion and virulence. Biology, 2(4): 1242-1267.

50. Han, J., David, D.E., Deck, J., Lynne, A.M., Kaldhone, P., Nayak, R., Stefanova, R. and Foley, S. (2010) Comparison of Salmonella enterica serovar Heidelberg isolated from human patients with those from animal and food sources. $J$. Clin. Microbiol., 49(3): 1130-1133.

51. Vohra, P., Bugarel, M., Turner, F., Loneragan, G.H., Hope, J.C., Hopkins, J. and Stevens, M.P. (2018) Quantifying the survival of multiple Salmonella enterica serovars in vivo via massively parallel whole-genome sequencing to predict zoonotic risk. Appl. Environ. Microbiol., 84(4): e 02262-17.

52. Gebreyes, W.A. and Thakur, S. (2005) Multidrug-resistant Salmonella enterica serovar Muenchen from pigs and humans and potential inter-serovar transfer of antimicrobial resistance. Antimicrob. Agents Chemother., 49(2): 503-511.

53. Zhao, S., White, D.G., Friedman, S.L., Glenn, A., Blickenstaff, K., Ayers, S.L., Abbott, J.W., HallRobinson, E. and McDermott, P.F. (2008) Antimicrobial resistance in Salmonella enterica serovar Heidelberg isolates from retail meats, including poultry, from 2002-2006. Appl. Environ. Microbiol., 74(21): 6656-6662.

54. Machado, S.A., Pereira, V.A., Aquino, M.C., Santos, A.M., Rodrigues, D.P., Giombelli, A. and Nascimento, E.R. (2017). Serotyping and genotyping of Salmonella strains isolated from broilers, chicken carcasses before and after chilling, and frozen chicken breasts produced in the states of Mato Grosso do Sul and Santa Catarina, Brazil. Braz. J. Poult. Sci., 19(1): 135-142.

55. Kebede, A., Kemal, J., Alemayehu, H. and Mariam, S.H. (2016) Isolation, identification, and antibiotic susceptibility testing of Salmonella from slaughtered bovines and ovines in Addis Ababa Abattoir Enterprise, Ethiopia: A cross-sectional study. Int. J. Bacteriol., 2016): 3714785.

56. Lin, D., Yan, M., Lin, S. and Chen, S. (2014). Increasing prevalence of hydrogen sulfide-negative Salmonella in retail meats. Int. J. Food Microbiol., 43: 1-4. 